\title{
COMPETENCIA JUDICIAL INTERNACIONAL Y MEDIDAS CAUTELARES: HACIA UNA TUTELA CAUTELAR EN EL PROCESO CIVIL EUROPEO CONVERGENTE CON LOS ORDENAMIENTOS NACIONALES
}

\author{
INTERNATIONAL JURISDICTION AND PROVISIONAL \\ MEASURES: TOWARDS A COMMON INTERIM JUSTICE \\ IN EUROPEAN CIVIL PROCEDURE CONVERGING ON \\ NATIONAL LAWS
}

\author{
Juan Carlos Ortiz-Pradillo \\ Profesor Titular de Derecho Procesal \\ Universidad Complutense de Madrid \\ Instituto de Derecho Europeo e Integración Regional (IDEIR)
}

Recibido: 19.06.2020 / Aceptado: 01.07.2020

DOI: https://doi.org/10.20318/cdt.2020.5674

\begin{abstract}
Resumen: La obtención y ejecución de medidas cautelares y provisionales en el ámbito de aplicación del Derecho Internacional Privado de la Unión Europea constituye una materia que aún debe solventar diversas e importantes cuestiones controvertidas. Pese a la evolución efectuada en dicha materia con el Reglamento 1215/2012 y con la jurisprudencia del TJUE, sigue sin estar claro el concepto de medida cautelar, la posibilidad de su solicitud con anterioridad a la sustanciación del asunto principal o la eficacia transfronteriza de las medidas adoptadas sin audiencia de la parte contraria. No obstante, en los últimos trabajos y propuestas de la Unión Europea para la armonización del Proceso Civil de la Unión, apreciamos una cierta tendencia a tratar de consagrar un régimen unitario de la tutela cautelar en el Espacio judicial europeo, caracterizado por admitir tanto la tutela cautelar solicitable ante causam como la adoptable inaudita parte debitoris y su eficacia transfronteriza más allá del Estado en que fue acordada.

Palabras clave: medidas cautelares, Reglamento Bruselas I bis, armonización, Proceso Civil Europeo, tutela cautelar.

Abstract: The obtaining and enforcement of protective and provisional measures in cross-border cases under the European Regulations in International Private Law is a matter which has yet to deal with some controversial issues. Despite the progress made with Regulation (EU) No 1215/2012 and the CJEU case-law, it remains unclear its definition, the possibility of its request prior to the determination of the court having jurisdiction on the substance of the matter, or the cross-border enforcement of the measures ordered without the defendant being summoned to appear. However, within the last Union's legislative works and proposals in the field of the harmonisation of the Civil Procedure, it must be

${ }^{*}$ Este trabajo fue preparado para ser defendido en el Seminario «Hacia un proceso civil convergente con Europa: balance de situación», dirigido por los Profs. Fernando Gascón InChausti y Pilar PeiteAdo MARISCAL, que debería haberse celebrado en la Facultad de Derecho de la UCM el 25 de junio de 2020 y que tuvo que ser suspendido como consecuencia de la pandemia asociada al Covid-19. Es uno de los resultados del Proyecto de Investigación "Hacia un proceso civil convergente con Europa. Hitos presentes y retos futuros" (PGC2018-094693-B-I00), financiado por el Ministerio de Ciencia e Innovación. Agradeceré el envío de cualquier crítica, sugerencia o comentario: juancarlosortiz@ucm.es.
\end{abstract}


highlighted a tendency to enshrine a common regime for the interim Justice in the European Judicial Area. And that common regime is characterised by admitting both the provisional measures requested prior to the main claim and the cross-border effectiveness of the ex parte measures beyond the State in which they were ordered.

Keywords: provisional measures, Regulation Brussels I Recast, harmonisation, European civil procedure, interim justice.

Sumario: I. Introducción: la tutela judicial efectiva como motor de armonización y como fundamento de la tutela cautelar en el ámbito transfronterizo. 1. El peligro de inefectividad en los litigios transfronterizos. II. Limitaciones de la tutela cautelar en el Derecho Procesal Civil de la Unión Europea. 1. Limitaciones a la extraterritorialidad de la tutela cautelar. 2. Limitaciones a la tutela cautelar ante causam. A) La generalización de la tutela cautelar ante causam en el plano interno. B) La excepcionalidad de la tutela cautelar ante causam en el plano transfronterizo. 3. Limitaciones a la tutela cautelar inaudita parte debitoris. A) La doctrina «Denilauler» y el rechazo al exequátur de medidas cautelares inaudita parte. B) Los avances del Reglamento Bruselas I bis respecto de las medidas cautelares con contradicción diferida. III. Reflexión final: hacia la consagración de la tutela cautelar ante causam e inaudita parte en el Derecho Procesal Civil de la Unión Europea.

\section{Introducción: la tutela judicial efectiva como motor de armonización y como fundamento de la tutela cautelar en el ámbito transfronterizo}

1. Existe una evidente interconexión entre el ejercicio de la potestad jurisdiccional (art. 117.3 $\mathrm{CE}$ ) y la tutela judicial que se deriva de dicho ejercicio (art. $24 \mathrm{CE}$ ), pues si la actividad genérica de la Jurisdicción es la aplicación del Derecho objetivo («aplicación de la ley $\left.{ }^{1} »\right)$, la citada interconexión significa que el ejercicio de la potestad jurisdiccional debe desembocar en una resolución «efectiva». Y en este sentido, la efectividad del derecho a la tutela judicial proclamada por el art. 24.1 de la Constitución requiere para su consecución una serie de mecanismos, medios o potestades, y entre los mismos, las medidas cautelares se muestran como uno de dichos mecanismos tendentes a garantizar la efectividad de la tutela judicial que recaiga en el proceso concreto ${ }^{2}$.

2. En consecuencia, el fundamento de las medidas cautelares es el derecho constitucionalmente reconocido a que la tutela judicial otorgada por los órganos jurisdiccionales sea efectiva ${ }^{3}$. El derecho a la tutela judicial debe poder asegurar el cumplimiento práctico de la resolución que en su día se dicte para cumplir así con la exigencia constitucional de ser una tutela eficaz, de modo que el fundamento

\footnotetext{
${ }^{1}$ Hasta la Ley Orgánica del Estado de 1967, y con la salvedad de la Constitución de 1931, todas las Constituciones promulgadas desde 1812 señalaban que el contenido de la potestad jurisdiccional era aplicar las leyes (art. $242 \mathrm{CE} 1812$; art. $63 \mathrm{CE}$ 1837; art. 66 CE 1845; art. 67 CE 1856; art. 91 CE 1869; art. 76 CE 1876). Vid., F. Garrido Falla, F., en VV.AA., Comentarios a la Constitución, Civitas, 1980, p. 1645.

2 Por ello, Calamandrei (Introduzione allo studio sistematico dei provvedimenti cautelari, Cedam, Padua, 1936, p. 22) las calificó de «instrumento del instrumento». En este sentido, PICó I JunOY (Las garantías constitucionales del proceso, Bosch, Barcelona, 1997, p. 69) señala tres materias que inciden en la efectividad de la tutela judicial: la inmodificabilidad de la sentencia o eficacia de cosa juzgada, las medidas cautelares, y la ejecución de las resoluciones firmes. Y Garberí Llobregat (Las Medidas Cautelares en la Nueva Ley de Enjuiciamiento Civil. Doctrina, Jurisprudencia y Formularios. Thomson Aranzadi, Navarra, 2004, p. 33) entiende como mecanismos para conseguir que la tutela judicial sea efectiva: $1^{\mathrm{o}}$ de manera preliminar, la instauración de un adecuado régimen de medidas cautelares, y $2^{\circ}$ con posterioridad, el perfeccionamiento del sistema de ejecución de los pronunciamientos de los tribunales.

3 Vid., entre otros, F. Ramos Méndez, "Las medidas cautelares indeterminadas en el proceso civil", Justicia, 1985, núm. I, pp. 75-90.; F. Chamorro Bernal, La tutela judicial efectiva. Derechos y garantías derivados del art. 24.1 de la Constitución, ed. Bosch, Barcelona, 1994, p. 283 y ss.; M. A. Jové Pons, Medidas cautelares innominadas en el proceso civil, ed. J. M. Bosch, Barcelona, 1995. p. 65; M. Ortells Ramos, P. CAlderón CuAdrado, La tutela judicial cautelar en el derecho español, ed. Comares, Granada, 1996, p. 3; J. L. VÁzQuEz Sotelo, "La configuración de las medidas cautelares en el anteproyecto de LEC", en VV.AA., Presente y Futuro del Proceso Civil (Coord. J. Picó I Junoy), ed. Bosch, Barcelona, 1998, p. 679; I. Dízz-Picazo GimÉnez, Derecho Procesal Civil. La ejecución forzosa. Procesos especiales, ECERA, Madrid, 2000, p. 379 y ss.
} 
constitucional de las medidas cautelares no se debe centrar en el aspecto general del derecho a la tutela, sino específicamente en el derecho a la efectividad de la misma ${ }^{4}$.

3. Por ello, aunque la fundamentación de la tutela cautelar sobre la base de la tutela judicial efectiva dio pie a la doctrina a derivar dicho fundamento del derecho a que el fallo se cumpla ${ }^{5}$, el Tribunal Constitucional, no obstante, ha establecido de forma expresa y directa el fundamento de la tutela cautelar dentro del derecho de acción del art. 24.1 CE, señalando, de una parte, que «la tutela judicial ha de ser, por imperativo constitucional, «efectiva», y la medida en que lo sea o no ha de hallarse en la suficiencia de las potestades atribuidas por ley a los órganos del poder judicial para, efectivamente, salvaguardar los intereses o derechos cuya protección se demanda» (STC 238/1992, de 17 de diciembre), y más concretamente, que «la tutela judicial efectiva no es tal sin medidas cautelares que aseguren el efectivo cumplimiento de la futura resolución definitiva que recaiga en el proceso ${ }^{6} \gg$ (STC 14/1992, de 10 de febrero).

4. En la Unión Europea, el principio de tutela judicial efectiva es un principio general del Derecho comunitario que resulta de las tradiciones constitucionales comunes a los Estados miembros y ha sido consagrado en los artículos 6 y 13 del Convenio Europeo para la protección de los Derechos Humanos y de las libertades fundamentales y reafirmado en el artículo 47 de la Carta de los Derechos Fundamentales de la Unión Europea.

5. Es más, la búsqueda de una tutela judicial efectiva es uno de los motores que impulsan la construcción de un espacio judicial europeo porque permite a la Unión Europea (art. 81 TFUE) aprobar instrumentos legislativos que favorezcan la armonización de las legislaciones nacionales, sobre la base de articular una cooperación judicial en asuntos civiles con repercusión transfronteriza, basada en el principio de reconocimiento mutuo de las resoluciones judiciales y extrajudiciales.

6. En el Derecho Procesal Civil Europeo, la posibilidad — que constituye el objeto del presente análisis- de que un órgano jurisdiccional, distinto del competente para conocer el litigio principal, pueda conocer de la pretensión cautelar supone asumir ese fundamento de velar por una tutela judicial efectiva, en el sentido de que el tribunal llamado a conocer de la tutela cautelar asume una "función de garante de los derechos de los justiciables no sólo en su territorio, sino también en el territorio de otro Estado; y es que su actividad en relación con las medidas cautelares tiende a asegurar la efectividad de una hipotética sentencia que se dicte por un tribunal extranjero en favor de quien sea actor en ese proceso ${ }^{7 "}$.

7. Para llevar a cabo dicho análisis, tomaremos como objeto de estudio la tutela cautelar transfronteriza recogida en el régimen establecido en el Reglamento (UE) núm. 1215/2012 del Parlamento

\footnotetext{
${ }^{4}$ F. Chamorro Bernal, La tutela judicial efectiva, op. cit., p. 286.

${ }^{5}$ La STC 32/1982, de 7 de junio, F.J. $2^{\circ}$, estableció por primera vez que «el derecho a la tutela efectiva no agota su contenido en la exigencia de que el interesado tenga acceso a los Tribunales de justicia, ni se limita a garantizar la obtención de una resolución de fondo fundada en derecho, sea o no favorable a la pretensión formulada. Exige también que el fallo judicial se cumpla y que el recurrente sea repuesto en su derecho y compensado, si hubiere lugar a ello, por el daño sufrido; lo contrario sería convertir las decisiones judiciales y el reconocimiento de los derechos que ellas comportan en favor de alguna de las partes, en meras declaraciones de intenciones». Así, F. RAmos Méndez (Comentarios a la Ley de Enjuiciamiento Civil, (Coord. V. Cortés Domínguez) ed. Tecnos, Madrid, 1985, pp. 689 y ss.) fundamentó la efectividad futura de la sentencia en la relación existente entre el art. $118 \mathrm{CE}$ - obligado cumplimiento de las resoluciones firmes de los Jueces y Tribunales-y el art. 18.2 LOPJ - ejecución de las sentencias en sus propios términos, y si la ejecución resultare imposible, adopción de medidas necesarias que aseguren la mayor efectividad de la ejecutoria-. Por ello, el fundamento de las medidas cautelares se ha relacionado con la potestad jurisdiccional establecida en el art. 117.3 CE (L. Prieto-Castro Ferrándiz, Tratado de Derecho Procesal civil, vol. II, $2^{\text {a }}$ edic., ed. Aranzadi, pamplona, 1985, Libro V, p. 847; J. Montero ArocA, "Medidas cautelares", en Trabajos de Derecho Procesal, ed. Librería Bosch, Barcelona, 1988, p. 444).

${ }^{6}$ La doctrina del Tribunal Constitucional más destacable en materia cautelar se recoge en las SSTC 66/1984, de 6 de junio; 115/1987, de 7 de julio; 202/1987, de 17 de diciembre; 237/1991, de 12 de diciembre; 14/1992, de 10 de febrero; 238/1992, de 17 de diciembre; 148/1993, de 29 de abril; 210/1993, de 28 de junio; 218/1994, de 18 de julio; 27/1995, de 6 de febrero; 39/1995, de 13 de febrero de 1995; 182/2000, de 10 de julio, y STC 159/2008, de 2 de diciembre.

${ }^{7}$ F. Gascón Inchausti, "Capítulo X. Medidas cautelares (art. 31 RB)", en VV.AA., Derecho Procesal Civil Europeo. Volumen I. (Dir. A. De La Oliva SAntos; Coord. F. Gascón InChausti), Aranzadi Thomson Reuters, 2011, p. 311.
} 
Europeo y del Consejo, de 12 de diciembre de 2012, relativo a la competencia judicial, el reconocimiento y la ejecución de resoluciones judiciales en materia civil y mercantil -en adelante, RB I-bis-, cuyo art. 35 establece que «Podrán solicitarse a los órganos jurisdiccionales de un Estado miembro medidas provisionales o cautelares previstas por la ley de dicho Estado miembro, incluso si un órgano jurisdiccional de otro Estado miembro es competente para conocer del fondo del asunto».

\section{El peligro de inefectividad en los litigios transfronterizos}

8. Con carácter general, los presupuestos necesarios para adoptar una resolución cautelar que proteja provisionalmente el derecho invocado por la parte son, tal y como se ha admitido mayoritariamente $^{8}$, el fumus boni iuris o apariencia de buen derecho, el periculum in mora o peligro por la mora del proceso, y la prestación de una contracautela suficiente para responder por los daños y perjuicios que la adopción de las medidas haya provocado a la parte afectada por las mismas para el caso de que la sentencia no estime lo garantizado provisionalmente.

9. De ellos, interesa destacar la especial importancia que juega la acreditación del periculum in mora en los litigios transfronterizos, pues a la hora de demostrar indiciariamente el existente riesgo de insatisfacción de su pretensión, si no se adoptan de forma provisional medidas que garanticen la ulterior efectividad de dicha sentencia, siempre se ha defendido que la propia duración del proceso conlleva ciertos peligros; en concreto, un específico peligro de daño marginal derivado precisamente de la tardanza en la emisión de la resolución definitiva y capaz de dificultar la efectividad de la tutela judicial dispensada por los órganos jurisdiccionales".

10. El peligro de inefectividad al que atienden las medidas cautelares se encuentra integrado por tres elementos: la nota temporal del proceso, el daño marginal inminente que puede producirse durante esa demora, y la ineficacia de la sentencia estimatoria de la pretensión actora a causa de dicho daño marginal. Además, se han distinguido dos clases de periculum in mora: el peligro por la mora del proceso (peligro objetivo), que trae su causa de la propia duración que implica necesariamente el proceso, y el peligro de insatisfacción (peligro subjetivo), referido a aquellos hechos o conductas de la parte demandada $-\mathrm{y}$ no a su simple cualidad ${ }^{10}$, , durante la tramitación que conlleva el proceso, que dificulten o impidan la posterior efectividad de la resolución definitiva (suspectio debitoris).

11. Ese peligro, tanto objetivo como subjetivo, se ve acentuado en los litigios transfronterizos, cuya duración temporal es considerable, lo que posibilita que el patrimonio del deudor disminuya e, incluso, sea enajenado para dificultar el cobro por parte del acreedor ${ }^{11}$. De ahí que el propio TJUE, en su

\footnotetext{
${ }^{8}$ Junto con estos tres elementos, ciertos autores establecen presupuestos específicos como por ejemplo la «necesaria pendencia del proceso» (vid. M. Serra Domínguez, F. Ramos Méndez, “Teoría general de las medidas cautelares”, en Las medidas cautelares en el proceso civil, ed. Industrias M. Pareja, Barcelona, 1974, pp. 11 y ss. pp. 34 y ss.; la «proporcionalidad» (vid. S. Barona Vilar, "Tutela cautelar en materia de propiedad intelectual”, Cuadernos de derecho y comercio, 1997, n 24, p. 225; la «menor onerosidad» (I. DíEz-Picazo Giménez, Derecho Procesal Civil, op. cit., p. 385; o la «idoneidad» (J. Garberí Llobregat, Las Medidas Cautelares en la Nueva Ley..., op. cit., p. 45).

${ }_{9}$ Calamandrei (Introduzione..., op. cit., p. 18) definía el periculum in mora como «el peligro de aquel ulterior daño marginal que podría derivarse del retraso de la resolución definitiva». La expresión «peligro de daño marginal» es de E. FinZI, "Questioni controverse in tema de esecuzione provvisorio", Riv. Dir. Proc. Civ., 1926, núm. 2, p. 49.

${ }^{10}$ Para la Audiencia Provincial de Castellón (Auto núm. 160/2012, secc. $3^{\text {a }}$, de 28 de septiembre) no es suficiente el hecho de que el demandado sea de nacionalidad extranjera, si no se acredita la concurrencia de otros elementos. Cfr., el Auto del Juzgado de lo Mercantil núm. 2 de Madrid de 9 de diciembre de 2014 (Procedimiento núm. 707/2014) en el que se hizo especial hincapié en que «la situación se hace más grave si tenemos en cuenta que la futura demandada desarrolla su actividad desde el paraíso fiscal estadounidense de Delaware, y se presenta según los notorios medios de comunicación con una deliberada vocación de opacidad, según indiciariamente consta con la documental presentada con la solicitud, lo que podría suponer una facilidad para situarse al margen de las leyes españolas y europeas».

11 A. L. Calvo Caravaca, J. Carrascosa González ("Medidas provisionales y cautelares y Reglamento Bruselas I-bis", Riv. dir. int. priv. e proc., 2015, núm. 1, pp. 55-78) también apuntan el hecho de que los tribunales estatales sólo tienen "poder
} 
Sentencia St. Paul Dairy, declarase (respecto del Convenio de Bruselas de 1968) que "la excepción a la competencia prevista en el artículo 24 del Convenio, pretende evitar a las partes el perjuicio resultante del alargamiento de los plazos inherentes a todo procedimiento internacional ${ }^{12}$ ".

12. Es más, dentro de ese fundamento común de articular instrumentos que faciliten la efectividad de las resoluciones judiciales que se dicten en el Espacio Judicial Europeo, el peligro de demora constituye uno de los leitmotiv que dan pie a las especialidades de la tutela cautelar del Derecho Procesal Civil Europeo aquí examinadas: la disociación a la hora de solicitar y conceder pretensiones cautelares que garanticen la efectividad de la pretensión discutida en el litigio principal. Siendo la regla general que la competencia para la tutela cautelar recaiga sobre el mismo órgano que conoce de la pretensión principal $^{13}$, el sistema europeo establece una importante excepción que autoriza a un órgano jurisdiccional de un Estado a resolver sobre una solicitud de medida provisional o cautelar aunque no sea competente para conocer del fondo del litigio.

13. El especial régimen establecido en el art. 35 RB I-bis, que posibilita solicitar la adopción de medidas cautelares a un tribunal de un Estado distinto del que conoce del asunto principal, se justifica en atención al principio de efectividad de la tutela que los tribunales han de dispensar para aquellos supuestos excepcionales en los que exista un Estado en donde el peligro de inefectividad se pueda conjurar más eficazmente que en el Estado ante el cual se tramita el proceso principa ${ }^{14}$. Y ese peligro de inefectividad también sirve de fundamento para posibilitar al Estado ante el que se solicita la ejecución de la resolución principal dictada en el Estado de origen (régimen del art. 40 RB I-bis) la adopción de medidas cautelares en tanto se procede a dicha ejecución ${ }^{15}$.

\section{Limitaciones de la tutela cautelar en el Derecho Procesal Civil de la Unión Europea}

14. No existe apenas discusión en reconocer que la nota característica por excelencia de las medidas cautelares es la instrumentalidad, la cual trae su causa del propio art. 24.1 CE en el sentido explicado anteriormente: la tutela judicial debe ser efectiva y las medidas cautelares se configuran como un instrumento para garantizar la efectividad de la tutela judicial que se otorgue finalmente en la sentencia dictada en el proceso principal (arts. 721.1 y $726.1 .1^{\circ}$ LEC).

15. Hablamos de instrumentalidad porque las medidas cautelares se configuran como un instrumento destinado a lograr la efectividad de la resolución jurisdiccional definitiva. En palabras de GuAsP,

efectivo" en el territorio en el que ejercen su función jurisdiccional, mientras que el deudor puede mover su patrimonio desde un Estado a otro para evitar ese poder territorial del Estado, de modo que las medidas cautelares "internacionales" servirían para reducir este peligro. En la misma línea, GARCíA GutiérReZ ("La tutela cautelar en las recientes reformas del derecho internacional privado español”, Anuario Español de Derecho Internacional Privado, 16, 2016, p. 284) recuerda que los procesos con vínculos internacionales tienden a durar más que los internos; es preciso hacer notificaciones al extranjero, obtener pruebas más allá del foro y, en numerosas ocasiones, es preciso acreditar o investigar también el contenido y vigencia de un Derecho extranjero.

${ }_{12}$ STJCE St. Paul Dairy, de 28 de abril de 2005 (Asunto C-104/03).

${ }^{13}$ STJCE Van Uden, de 17 de noviembre de 1998 (Asunto 391/95), aptdo. 22: “el órgano jurisdiccional competente para conocer del fondo de un asunto en virtud de uno de los criterios de competencia previstos en el Convenio sigue siendo también competente para adoptar medidas provisionales o cautelares, sin que esta última competencia esté supeditada al cumplimiento de otros requisitos". Afirmación refrendada posteriormente en la STJCE Mietz, de 27 de abril de 1999 (Asunto 99/96), aptdo. 41.

${ }^{14}$ F. J. Garcimartín AlfÉrez, El régimen de las medidas cautelares en el comercio internacional, Madrid, McGraw-Hill, 1996, op. cit., p. 72.

${ }^{15}$ BACHMAIER Winter (“Artículo 40”, en VV.AA., Comentario al Reglamento (UE) $n^{\circ}$ 1215/2012 relativo a la competencia judicial, el reconocimiento y la ejecución de resoluciones judiciales en materia civil y mercantil, (coords. P. BLANCO-MORALES Limones, F. F. Garau Sobrino, M. L. Lorenzo Guillén, F. J. Montero Muriel, Thomson Reuters Aranzadi, 2016, p. 793) señala que la respuesta a esta posibilidad de acordar medidas cautelares sobre la base de un título que ya conlleva fuerza ejecutiva es "sencilla y paradójica: con la adopción de medidas cautelares se pretende neutralizar el riesgo que la demora del propio proceso de ejecución puede conllevar; y lo paradójico es que los procesos de ejecución puedan implicar una demora tal que haga necesario que el ejecutante solicite la adopción de medidas cautelares para asegurar el resultado de esa ejecución”. 
cumple una finalidad garantizadora del cumplimiento de las otras dos clases de tutela ${ }^{16}$. Por ello, frente a las tradicionales potestades "declarativa" y "ejecutiva", la cautelar se configura como un tertium genus que no da lugar a un proceso autónomo como tal, sino que la misma goza de cierta autonomía procedimental.

16. Esta autonomía procedimental significa que la tutela cautelar se lleva a la práctica a través de un procedimiento o incidente conformado por fases diferenciadas entre sí (solicitud, valoración, adopción o denegación, oposición e impugnación, ejecución, modificación y alzamiento), pero dentro de otro proceso - al que se denomina «proceso principal»- y por el mismo órgano jurisdiccional que conoce o debe conocer de ese proceso principal ${ }^{17}$.

17. En el plano transfronterizo, sin embargo, esa "autonomía procedimental" conlleva la siguiente disociación: otro órgano judicial de otro Estado puede conocer del procedimiento cautelar. Es lo que se ha llamado la excepción en materia de las reglas de competencia, llegando a ser tildado de «elemento perturbador» del régimen establecido en materia de competencia judicial internacional ${ }^{18}$.

18. El hecho de que la tutela cautelar pueda ser pretendida ante un tribunal de un foro extranjero (distinto al competente para resolver el litigio principal) resulta crucial y da lugar, de una parte, a que dicho tribunal actúe conforme a sus reglas procesales internas en lo que se refiere al procedimiento cautelar a seguir tras la solicitud, que se acomodará a lo previsto en la normativa procesal interna conforme al tradicional axioma lex fori regit processum. $\mathrm{Y}$ de otra parte, a que las medidas a adoptar serán aquellas previstas en la legislación interna del Estado requerido y no las recogidas en el Ordenamiento del Estado en el cual se sigue el proceso de fondo ${ }^{19}$.

19. Ello ha obligado a determinar, en primer lugar, a qué se refiere el art. 35 RB I-bis (heredero del art. 31 del Reglamento 44/2001, y éste, a su vez, del art. 24 del Convenio de Bruselas) cuando habla de «medidas provisionales o cautelares», exigiendo efectuar un importante análisis de las diferentes versiones lingüísticas del RB I-bis para llegar a la conclusión de que no se trata de realidades diferentes, sino que las medidas cautelares, de aseguramiento o de protección serían una subespecie de las provisionales $^{20}$.

20. Además de ello, y con independencia de que los Estados atiendan a la regulación cautelar prevista en sus ordenamientos internos, deberán tener presente la interpretación supranacional de dicho Reglamento en manos de su intérprete supremo: el TJUE, quien a través de consolidada jurisprudencia se ha decantado por establecer un concepto autónomo de medida cautelar, ajeno a las posibles diferencias nacionales, y las concibe como medidas caracterizadas por su provisionalidad e instrumentalidad, destinadas a mantener una situación de hecho o de derecho para salvaguardar derechos cuyo reconocimiento se solicita, con los requisitos típicos de fumus boni iuris y periculum in mora - además de permitir que el órgano judicial pueda solicitar determinadas garantías al demandante-, con un vínculo

16 J. Guasp, Derecho Procesal Civil, tomo II, $3^{\text {a }}$ edic., Instituto de Estudios Políticos, Madrid, 1968, p. 683, define el proceso cautelar como «aquel que tiene por objeto facilitar otro proceso principal garantizando la eficacia de sus resultados».

${ }^{17}$ Como especialidad, el art. 725.2 LEC permite que un tribunal territorialmente incompetente para conocer del proceso principal adopte en prevención las medidas cautelares que considere más urgentes.

18 A. Dickinson, "Provisional Measures in the Brussels I Review: Disturbing the Status Quo", Journal of Private International Law, vol. 6, $\mathrm{n}^{\circ} 3$, December 2010, pp. 519-564. Para dicho autor, el régimen finalmente incorporado en el art. 31 (Reglamento 44/2001) no sólo no consiguió el propósito de fijar reglas de competencia judicial internacional "altamente predecibles", sino que se trata de una excepción a la competencia del domicilio del demandado (artículo 2) y crea un panorama no uniforme (non-uniform landscape) en el que no es posible que los litigantes determinen únicamente sobre la base del Reglamento si un concreto tribunal es o no competente para conceder medidas provisionales.

${ }^{19}$ El propio art. 35 RB I-bis así lo afirma, al referirse a las medidas "previstas por la ley de un Estado miembro". Y tal afirmación resulta pacífica en la doctrina. Vid. C. AlbRecht, Das EuGVÜ und der einstweilige Rechtsschutz in England und in der Busdesrepublik Deutschland. Carl Winter Verlag, Heidelberg, 1991, p. 84 y ss.; E. MerLin, "Le misure provvisorie e cautelari nello spazio giudiziario europeo", Riv. Dir. Proc., 2002, n³, p. 769.

${ }^{20}$ F. Gascón InChausti, "Capítulo X. Medidas cautelares (art. 31 RB)”, op. cit., p. 313. 
de conexión real entre su objeto y el juez que conoce del asunto, y cuya adopción respete las reglas de contradicción ${ }^{21}$.

21. Sin ánimo de entrar ahora a analizar dicha interpretación autónoma de la tutela cautelar por parte del TJUE ${ }^{22}$, lo cierto es que el régimen cautelar establecido en el Reglamento Bruselas I bis conlleva una serie de especialidades (en puridad, las denominaremos «limitaciones») que distorsionan, en parte, el alcance de esa pretendida efectividad de la tutela principal a garantizar y obstaculizan la libre circulación de las resoluciones judiciales en materia civil y mercantil en el Espacio judicial europeo. Esto es, precisamente, lo que buscamos poner de manifiesto con el presente estudio.

\section{Limitaciones a la extraterritorialidad de la tutela cautelar}

22. La primera especialidad derivada del régimen cautelar establecido en el RB I-bis, en el que puede disociarse entre el foro que conoce del proceso principal y aquél otro u otros que puedan conocer de pretensiones cautelares, se refiere al diferente alcance que puede tener dicha resolución cautelar según ésta haya sido adoptada por el mismo órgano jurisdiccional que esté conociendo o pueda conocer de la pretensión principal en virtud de cualquier foro de competencia judicial internacional de los recogidos en el Reglamento (arts. 4 a 26 RB I-bis); por el órgano jurisdiccional ante el que se solicite la medida cautelar para garantizar una pretensión principal que se tramite ante otra jurisdicción (art. 35 RB I-bis); o bien por el órgano jurisdiccional al que se requiera para ejecutar una resolución con fuerza ejecutiva en virtud de lo dispuesto en el Capítulo III del Reglamento (art. 40 RB I-bis).

23. A diferencia de lo dispuesto expresamente en los arts. 35 y 40 RB I-bis, la facultad cautelar del órgano judicial competente para conocer del fondo del asunto (litigio principal) no se encuentra recogida en precepto alguno del Reglamento, a diferencia de lo que sí ha hecho, internamente, el art. 22 sexies LOPJ. Ha sido el TJUE quien se ha ocupado de recordar expresamente que "el tribunal competente para conocer del fondo de un asunto en virtud de uno de los criterios de competencia previstos por el Convenio sigue siendo también competente para adoptar medidas provisionales o cautelares, sin que esta última competencia esté supeditada al cumplimiento de otros requisitos ${ }^{23}$ ". Y dicha facultad cautelar del foro principal, en principio, tendrá eficacia transfronteriza, a diferencia de la acordada por el foro auxiliar de los arts. 35 y 40 RB I-bis.

\footnotetext{
${ }^{21}$ Como principales Sentencias del TJUE en materia cautelar, véanse las Sentencias De Cavel, de 27 de marzo de 1979 (Asunto 143/78); De Cavel II, de 6 de marzo de 1980 (Asunto 120/79); CHW, de 31 de marzo de 1982; Denilauler, de 21 de mayo de 1980 (Asunto 125/79); C.H.W., de 31 de marzo de 1982 (Asunto 25/81); Reichert, de 26 de marzo de 1992 (Asunto C-261/90); Zuckerfabrik, de 21 de febrero de 1991 (Asuntos 143/88 y 92/89); Hatrex, de 10 de febrero de 1994 (Asunto 398/92); Atlanta, de 9 de noviembre de 1995 (Asunto 465/93); Van Uden, de 17 de noviembre de 1998 (Asunto 391/95); Mietz, de 27 de abril de 1999 (Asunto 99/96); Turner, de 27 de abril de 2004 (Asunto 159/02) o St. Paul Dairy, de 28 de abril de 2005 (Asunto C-104/03); y Meroni, de 25 de mayo de 2016 (Asunto C-559/14).

${ }^{22}$ Respecto a la concepción autónoma de «medidas cautelares», véanse los trabajos de L. CARrillo Pozo, Comentario al convenio de Bruselas relativo a la competencia judicial y a la ejecución de resoluciones judiciales en materia civil y mercantil (Coord. A. Calvo Caravaca), Universidad Carlos III de Madrid, Boletín Oficial del Estado, Madrid, 1994, pp. 432-457; F. J. Garcimartín Alférez, El régimen de las medidas cautelares..., op. cit., p. 73; M. A. FernÁndez-BAllesteros LóPez, "Las medidas cautelares «internacionales»”, Cuadernos de Derecho Judicial. CGPJ, Madrid, 1997, nXVII, p. 417; L. QuerzolA, "Tutela cautelare e convenzione di Bruxelles nell'esperienza della Corte di Giustizia delle Comunità europee", Riv. Trim. Dir. e Proc. Civ., 2000, fasc. 3, p. 831 y ss.; A. L. Calvo Caravaca y J. Carrascosa GonzÁlez, Legislación de Derecho Internacional Privado comentada y con jurisprudencia, ed. Colex, Madrid, 2002, p. 274; E. MerLin, “Le misure provvisorie...”, op. cit., p. 784 y ss.; F. Gascón InChausti, “Capítulo X. Medidas cautelares (art. 31 RB)”, op. cit., p. 313

${ }^{23}$ SSTJCE Van Uden, op. cit., aptdo. 22 y Mietz, op. cit., aptdo. 41. Por ello, Arenas García ("Las medidas provisionales y cautelares en el Reglamento Bruselas I: de la regulación actual a la regulación proyectada", Diario La Ley, № 7601, de 31 de marzo de 2011) entiende legítimo interrogarse sobre el fundamento de la atribución de dicha competencia en materia cautelar a los Tribunales que gozan de jurisdicción para pronunciarse sobre el fondo del asunto y defiende la necesidad de que dicha competencia se recogiese expresamente.
} 
24. Este dispar alcance o fuerza transfronteriza en función del foro que adopta la medida cautelar, catalogado como un régimen "coherente ${ }^{24 "}$, se explica de un modo sencillo en el considerando núm. 33 del Reglamento de 2012: la medida cautelar dictada por el órgano jurisdiccional que conoce del fondo del asunto podrá ser reconocida y ejecutada en otro Estado miembro en virtud del cauce previsto en el Capítulo III del mismo, al garantizarse su libre circulación y su consideración de «resolución» a los efectos previstos en los arts. 36 y ss. (art. 2, letra a). Por el contrario, cuando las medidas provisionales y cautelares sean ordenadas por un órgano jurisdiccional de un Estado miembro que no es competente en cuanto al fondo del asunto - foro alternativo en virtud del art. 35 RB I-bis-, su efecto queda limitado al territorio de ese Estado miembro.

25. Dicho régimen puede ser presentado como un sistema con dos modelos de tutela cautelar con alcances diferentes: uno extraterritorial (transfronterizo) ofuerte: el acordado por el foro que resulte competente para el asunto principal y cuya competencia, a su vez, podrá hacerse residenciar en cualquiera de las distintas reglas establecidas en las secciones del capítulo II RB I-bis o de otros Reglamentos especiales por razón de la materia. Y otro limitado (nacional) o débil: el acordado por el foro alternativo del art. 35 RB I-bis, cuya competencia dependerá de la localización de un «vínculo de conexión real» entre la pretensión cautelar y dicho foro, como por ejemplo pueda ser el Estado miembro donde estén situados los bienes que serán objeto de las medidas solicitadas ${ }^{25}$, tal y como prevé internamente nuestro art. 22 sexies LOPJ, o donde se persiga ejecutar la resolución principal, como dispone el propio art. 40 RB I-bis. No obstante, este sistema cautelar de doble vía y basado en esa disociación competencial, antes indicada, debe ser objeto de ciertas matizaciones.

26. Por lo que respecta al foro débil o auxiliar del art. 35 RB I-bis, éste no es tan débil o limitado si se tiene en cuenta que el mismo es considerado una norma de remisión a las reglas internas de competencia internacional en materia cautelar, incluso aunque éstas contengan foros exorbitantes, que sólo se aplican a la determinación de la competencia en cuanto al fondo (asunto principal) pero no para la petición caute$1 a r^{26}$. Además, esa eficacia territorial limitada al Estado en que se han acordado las medidas cautelares se ve compensada con la posibilidad de que las mismas se puedan acordar ante causam y/o inaudita altera parte, a lo cual nos referiremos más adelante. $\mathrm{Y}$ a todo ello debe sumarse la posibilidad de que las medidas cautelares adoptadas en virtud de dicho foro auxiliar sí puedan llegar a desplegar efectos extraterritoriales "de facto", sin necesidad de instar su exequatur en tales territorios, si las mismas se encuentran aseguradas mediante una astreinte o mediante otra sanción personal como el contempt of court inglés ${ }^{27}$.

27. En nuestra opinión, sin embargo, tales medidas "anti-proceso" no debieran ser adoptables, ni por el foro competente para conocer del proceso principal, ni tampoco por el foro auxiliar del art. $35 \mathrm{RB}$ I- bis, pues su incompatibilidad con el sistema del Reglamento ${ }^{28}$ trasciende de la distribución competencial del sistema (esto es, excede de la diferenciación entre foros exclusivos, exorbitantes, alternativos, etc.), ya que supone una injerencia contraria al mismo, al ir en detrimento de la eficacia del Convenio (entiéndase, ahora, el Reglamento. STJUE de 15 de mayo de 1990, C-365/88, asunto Hagen).

28. En España, por ejemplo, la jurisprudencia también ha rechazado la posibilidad de que un tribunal español acuerde como medida cautelar la suspensión de otro proceso iniciado en un Estado

${ }^{24}$ M. Virgós Soriano y F. J. Garcimartín Alférez, Derecho procesal civil internacional. Litigación internacional, Thomson/Civitas, 2. ${ }^{\text {a }}$ ed., 2007, p. 337.

${ }^{25}$ STJCE Denilauler, de 21 de mayo de 1980 (Asunto 125/79), aptdo. 16. Un ejemplo concreto de esa conexión real con el foro lo explicita el art. 471 de la Ley 14/2014, de 24 de julio, de Navegación Marítima, que al regular el embargo preventivo de buques, dispone que será competente, además del tribunal que tenga competencia objetiva para conocer de la pretensión principal, "el del puerto o lugar en que se encuentre el buque o aquel al que se espera que el buque arribe".

${ }^{26}$ STJCE Van Uden, aptdo. 42.

${ }^{27}$ En este sentido, F. GASCón InCHAUStI, “Capítulo X...”, op. cit., p. 334.

${ }^{28}$ Referidas al Reglamento 44/2001, vid. STJUE Turner, de 27 de abril de 2004 (Asunto C-159/02), posteriormente ratificada en la STJUE West Tankers, de 10 de febrero de 2009 (Asunto C-185/07). 
extranjero $^{29}$ (un procedimiento de ejecución hipotecaria ante el Tribunal de Gran Instancia de Bayona, Francia), pero sin referirse expresamente a la doctrina TJUE. Sus fundamentos han consistido, por una parte, en estimar que el art. 727 LEC no contempla como medida cautelar la suspensión de un procedimiento judicial y tampoco cabe incardinarla en el número 11 del referido artículo. Y por otra parte, porque las causas de suspensión en el proceso de ejecución hipotecaria están legalmente tasadas.

29. Por lo que respecta al foro fuerte o extraterritorial, referido al Estado competente para conocer del fondo del asunto, la utilización de los distintos fueros de competencia judicial internacional del RB I-bis permite cierto forum shopping para obtener medidas cautelares «espacialmente eficacísi$\operatorname{mas}^{30} \gg$, pero también se encuentra afectado por el régimen de los fueros de competencia exclusiva del sistema europeo. La medida cautelar acordada por el tribunal que está conociendo o va a conocer del asunto principal también puede tener una eficacia territorial limitada al país que la hubiera estimado si se hubiera acordado infringiendo un fuero de competencia exclusiva, algo que no afecta al foro auxiliar del art. 35 RB I-bis.

30. La imposibilidad de ejecutar una medida cautelar acordada contraviniendo un fuero exclusivo la establece el art. 42.2 RB I-bis, letra b, apartado i, que exige al solicitante que trata de que se ejecute esa medida cautelar en otro territorio el certificado expedido conforme al artículo 53, con una descripción de la medida y que acredite que el órgano jurisdiccional es competente en cuanto al fondo del asunto. La misma se incorporó a nuestro sistema interno a través de la Disposición final vigésima quinta LEC de Medidas para facilitar la aplicación en España del Reglamento (UE) núm. 1215/2012 del Parlamento y del Consejo, de 12 de diciembre de 2012, relativo a la competencia judicial, el reconocimiento y la ejecución de resoluciones judiciales en materia civil y mercantil.

31. En España, se ha defendido la exigencia de que el solicitante de la ejecución de la resolución cautelar presentare una copia fehaciente de la demanda iniciada en el extranjero, para así comprobar que el objeto del proceso allí seguido no versa sobre una competencia exclusiva de los tribunales españoles ${ }^{31}$. A ello se opone, de una parte, el hecho de que el asunto principal pudiera aún no estar lite pendente, y de otra parte, la prohibición general y radical de controlar la competencia judicial internacional del tribunal de origen (art. 45.3 RB I-bis), de modo que la sola afirmación del tribunal de origen que ha hecho constar en el certificado conforme al Anexo I debe ser suficiente ${ }^{32}$.

32. En nuestra opinión, esa imposibilidad de control de oficio de la competencia judicial internacional del tribunal del Estado que en origen acordó la medida cautelar que ahora se pretende ejecutar en España no impide que el sujeto contra quien se dirija tal ejecución pueda solicitar la denegación de la ejecución (art. 46 RB I-bis) porque la misma infrinja las reglas de competencias exclusivas de la sección 6 del capítulo II (art. 45.1.e RB I-bis).

33. Una cosa es que el solicitante cautelar pueda acudir al foro auxiliar del art. 35 RB I-bis para obtener una tutela cautelar limitada al territorio de dicho Estado, aunque sobre el fondo del asunto sea exclusivamente competente otro tribunal de otro Estado diverso, tal y como ha llegado a reconocer el propio TJUE en el asunto Solvay ${ }^{33}$, y otra cosa distinta es que se intente ejecutar en un territorio (Estado

\footnotetext{
29 AAP de San Sebastián, secc. 2a , núm. 36/2018, de 8 de marzo.

30 A. L. Calvo Caravaca y J. González Carrascosa, "Medidas provisionales y cautelares y Reglamento Bruselas I-bis", op. cit., p. 64 .

31 J. A. Robles Garzón, J. A., Comentarios Prácticos a la nueva Ley de Enjuiciamiento Civil, ed. Trivium, Madrid, 2000, p. 651 .

32 A. L. Calvo Caravaca y J. González Carrascosa, "Medidas provisionales y cautelares y Reglamento Bruselas I-bis", op. cit., p. 75, estiman que el juez del Estado miembro requerido, ante tal certificado, no podrá revisar la competencia judicial internacional del juez del Estado de origen.

33 STJUE Solvay, de 12 de julio de 2012 (Asunto C-616/10), aptdos. 49 a 51: "En estas circunstancias, parece que no existe el riesgo de contradicciones entre las resoluciones (...) si la resolución provisional adoptada por el juez que conoce con carácter
} 
de ejecución) una medida cautelar acordada por un tribunal de otro Estado (Estado de origen), cuando la competencia para conocer del fondo del asunto se encontrase atribuida con carácter exclusivo a los tribunales de ese Estado en que se pretende ejecutar la medida.

34. Si los tribunales españoles tienen prohibida la ejecución de medidas cautelares acordadas por otro Estado que hubiera vulnerado un fuero de competencia exclusiva de la jurisdicción española, con mayor motivo deberían rechazar la solicitud de adopción de medidas cautelares para asegurar la efectividad de ese proceso seguido ante unos tribunales que han infringido dicha competencia exclusiva de la jurisdicción española. Esto es, como limitación adicional a la eficacia territorial de la regla dispuesta en el art. 35 RB I-bis, no podrán solicitarse a los tribunales españoles medidas cautelares para asegurar el resultado del proceso extranjero cuando los tribunales españoles resultaran ser exclusivamente competentes para conocer del fondo del litigio en virtud de una regla de competencia judicial internacional exclusiva prevista en el Reglamento, pues el tenor del art. 722.II LEC resulta claro a la hora de excepcionar aquellos supuestos en los que para conocer del asunto principal sean exclusivamente competentes los tribunales españoles ${ }^{34}$.

\section{Limitaciones a la tutela cautelar ante causam}

\section{A) La generalización de la tutela cautelar ante causam en el plano interno}

35. La pendencia del proceso, presente o futura, es una consecuencia de la instrumentalidad de la tutela cautelar y no una característica aparte ${ }^{35}$, pues si las medidas cautelares se configuran como un instrumento destinado a asegurar provisionalmente la efectividad de la tutela judicial, tendrán lugar dentro de un proceso en el cual se reclame dicha tutela. No tiene sentido solicitar el aseguramiento provisional de los efectos de una resolución que no se ha requerido y que, por tanto, no se emitirá. Esta manifestación es establecida expresamente en el art. 731 LEC bajo el nombre de «accesoriedad» de la medida cautelar respecto del proceso principal dentro del cual se otorga, o más específicamente, respecto del objeto litigioso (pretensión) que en él se ventila ${ }^{36}$, de modo que si no existe dicha pretensión principal, desaparece la finalidad o razón de ser de la medida cautelar ${ }^{37}$.

incidental no prejuzga en modo alguno la resolución que, con arreglo al artículo 22, número 4, del Reglamento no 44/2001, deberá adoptar en cuanto el fondo el órgano jurisdiccional competente. A la luz de las consideraciones anteriores, procede responder a la segunda cuestión que el artículo 22, número 4, del Reglamento $n^{\circ}$ 44/2001 debe interpretarse en el sentido de que, en unas circunstancias como las controvertidas en el litigio principal, no se opone a la aplicación del artículo 31 de dicho Reglamento”. En el mismo sentido, vid. F. GASCón InCHAUSTI, “Artículo 35”, op. cit., p. 714.

${ }^{34}$ En nuestra opinión, los tribunales españoles no deberían garantizar cautelarmente una futura sentencia extranjera que nunca llegará a reconocerse y ejecutarse en España por haber infringido las competencias exclusivas fijadas en nuestro ordenamiento jurídico. Sin embargo, a favor de la solicitud cautelar en España, vid., F. J. GARCimartín Alférez, El régimen de las medidas cautelares..., op. cit., p. 115, y los allí citados. GASCón InCHAUSTI (Medidas cautelares del proceso civil extranjero, ed. Comares, Granada, 1998, p. 223) especifica que lo importante ha de ser si, aunque de un asunto conozcan o vayan a conocer de manera exclusiva los tribunales de un Estado, resulta necesario asegurar en otro Estado la efectividad de la sentencia que vaya a dictarse.

${ }^{35}$ Cfr. V. PÉrez DAudí ("Las medidas cautelares", en VV.AA., Instituciones del nuevo proceso civil. Comentarios sistemáticos a la ley 1/2000, de Enjuiciamiento Civil. Vol. III. (Coord., J. Alonso-Cuevillas SAYrol), ed. Difusión Jurídica, Barcelona, 2000 , pp. 558 y 599), quien rechaza que la pendencia del proceso deba ser catalogada como una nota secundaria deducida de la instrumentalidad, y la entiende como el cuarto presupuesto de las medidas cautelares.

${ }^{36}$ F. Ramos Méndez, Derecho Procesal Civil, tomo I, $4^{\mathrm{a}}$ edic., ed. Bosch, Barcelona, 1990, p. 950.

${ }^{37}$ Conforme al AAP Madrid, secc. $20^{\text {a }}$, núm. 1/2008 de 8 de enero, «La naturaleza accesoria propia de toda medida cautelar en relación al procedimiento principal adquiere especial importancia cuando, como en el caso presente, se solicita inaudita parte y sin existir procedimiento en el que se dilucide la cuestión de fondo cuya efectividad pretenda garantizar la medida interesada, de manera que denegada la medida y no constando exista entre las partes litigio alguno sobre la cuestión de fondo debatida, han desaparecido las razones de urgencia o necesidad que el artículo 730.2 LECiv exige para poderlas solicitar y por tanto para acordarlas, de manera que esas razones han desaparecido y con ellas la razón de ser o finalidad de la medida interesada, encontrándonos ante una situación equiparable a la carencia de objeto del procedimiento, lo que conlleva por sí solo la desestimación del recurso». 
36. Frente al momento "ordinario" para la solicitud de medidas cautelares (interposición de la demanda principal), el art. 730.2 LEC señala la posibilidad de solicitar la adopción de medidas cautelares con carácter previo a la interposición de la demanda «si quien en ese momento las pide alega y acredita razones de urgencia o necesidad» (solicitud ante causam). Y finalmente, resulta admisible dicha solicitud durante la tramitación del proceso principal si a resultas del devenir de dicho proceso se muestra conveniente y necesaria una protección provisional de lo que finalmente sea declarado.

37. Toda la tramitación cautelar debe verse impregnada por la nota de la brevedad procedimental, dada la celeridad requerida para que la tutela que posteriormente se declare en la sentencia definitiva pueda ser eficazmente llevada a la práctica ${ }^{38}$. Ahora bien, la tutela cautelar ante causam exige una particular «urgencia» (arts. 730 y 733 LEC) distinta a esa celeridad que ha de existir en sede cautelar ${ }^{39}$, pues viene referida a determinadas circunstancias que implican que la medida cautelar sea adoptada en el menor plazo posible, saltándose incluso algunas de las fases respecto de lo que constituye el procedimiento cautelar ordinario. Y de otra parte, la «necesidad» de esos mismos preceptos también difiere de la necesidad analizada como uno de los componentes de la proporcionalidad de las medidas cautelares.

38. Frente a la necesidad como concreción de la proporcionalidad, referida al deber del órgano jurisdiccional de adoptar aquella medida, no sólo idónea para asegurar la efectividad de la pretensión que pueda estimarse posteriormente en la sentencia definitiva, sino también aquélla que además resulte menos gravosa para la parte que debe soportar dicha medida, la LEC también se refiere a la «necesidad» de las medidas cautelares en un sentido distinto: como un requisito específico a la hora de solicitar y obtener las medidas, bien con anterioridad a la interposición de la demanda en el proceso principal (medidas ante causam, art. 730.2 LEC), o bien sin la celebración de una audiencia previa (medidas inaudita parte debitoris, art. 733.2 LEC).

39. Esta noción de «necesidad» también se menciona, por ejemplo, para la solicitud de medidas durante la suspensión del proceso principal por haberse interpuesto declinatoria (art. 64.2 LEC), para la adopción de medidas urgentes por parte de los Jueces Decanos y los Presidentes de Tribunales y Audiencias en los asuntos aún no repartidos (art. 70 LEC), o para la su solicitud sin representación de procurador ni asistencia letrada con anterioridad al juicio (arts. 23.2.3 $3^{\circ}$ y 31.2.2 ${ }^{\circ} \mathrm{LEC}$ ). En estos casos, «necesidad» significa urgencia en su adopción; que la medida pretendida sea adoptada en el menor plazo posible. Por ello, ha de distinguirse la «necesidad» como manifestación de la proporcionalidad dentro de las características de las medidas cautelares $\left(726.1 .2^{\circ}\right.$ LEC $)$ de aquella otra «necesidad» referida a la petición y adopción de medidas cautelares bajo circunstancias especiales (730.2 y 733.2 LEC).

40. Desde esta perspectiva, la urgencia y necesidad de la solicitud ante causam se refieren, no ya a la inminente necesidad de garantizar la efectividad de lo que se resuelva en el proceso principal mediante la adopción de la tutela cautelar, sino específicamente a la urgente necesidad de garantizar la efectividad de la propia medida que se solicita, en tanto se procede a tramitar la admisión a trámite de la demanda o la iniciación y sustanciación del proceso principal. Es decir, constituyen un periculum in mora cualificado $o^{40}$, derivado de la duración de la propia puesta en marcha del proceso y la realización de los trámites ordinarios para convocar el procedimiento cautelar.

${ }^{38}$ Compartimos el criterio de V. FAiRÉn GuILlÉN, "La reforma del proceso cautelar español”, en Temas del ordenamiento procesal, Tomo II, ed. Tecnos, Madrid, 1969, p. 901 y ss., para quien los elementos [caracteres] de las medidas cautelares producen la urgencia del procedimiento.

${ }^{39}$ Cfr. V. PÉrez Daudí, "El proyecto de Ley de enjuiciamiento civil y las medidas cautelares en el proceso de propiedad industrial”, La ley, 1999, v. 20, núm. 4717, pp. 1-7, quien advierte que la «urgencia y necesidad» deben predicarse respecto de toda medida cautelar, y no sólo de las medidas cautelares previas.

40 J. Massaguer Fuentes (“Las medidas cautelares en la ley de competencia desleal”, RDM, 1992, n²06, pp. 746 y 761) lo considera una «acentuación» del periculum in mora tradicional. En el mismo sentido, vid., F. GASCón Inchausti, La Adopción de Medidas Cautelares con Carácter Previo a la Demanda, ed. Cedecs, Barcelona, 1999, p. 43; I. Díez-Picazo Giménez, Derecho Procesal Civil, op. cit., p. 398; V. Pérez Daudí (en VV.AA., Comentarios a la Ley de Sociedades Anónimas, vol. II, (Coords., I. Arroyo Martínez / J. M. Embid Irujo), ed. Tecnos, Madrid, 2001, p. 1239). 
41. En palabras de la Audiencia Provincial de Madrid, «no puede confundirse con el peligro en la demora propio de todas las medidas cautelares y previsto en el art. 728.1 de la Ley de Enjuiciamiento Civil (si así ocurriera la solicitud de medidas cautelares con carácter previo quedaría desprovista de singularidad, y el requisito adicional del artículo 730.2 resultaría vaciado de significado), ni tampoco con la urgencia que justifica la posibilidad de adoptar las medidas cautelares sin audiencia del demandado, ya que puede estar justificada la urgencia o necesidad de adoptar unas medidas cautelares previas a la demanda porque su solicitud no pueda demorarse el tiempo necesario para pedirlas junto con la demanda, pero puede no concurrir la urgencia necesaria para adoptarlas inaudita parte porque no exista el menor riesgo de que su eficacia pueda quedar comprometida por el mero transcurso del tiempo necesario para cumplimentar los trámites de citación y celebración de la vista, ni se aprecie razón alguna para temer que el mero conocimiento de la parte demandada sobre la posibilidad de adoptar las medidas pudieran comprometer su buen $\mathrm{fin}^{41} \gg$.

42. No obstante lo anterior, la doctrina ha considerado que, aunque la LEC permita que la urgencia requerida para pedir medidas cautelares con carácter previo a la demanda y aquélla otra que permite su adopción inaudita parte pueden considerarse por separado, la regla general a considerar ha de ser que la urgencia y necesidad alegadas para solicitar medidas cautelares con anterioridad a la interposición de la demanda implican también la idea de que el solicitante cautelar pretenderá que tales medidas sean adoptadas sin audiencia previa ${ }^{42}$.

43. En nuestra opinión, sin embargo, la petición de medidas cautelares con anterioridad a la interposición de la demanda puede solicitarse con o sin audiencia previa a la parte pasiva de las mismas, según exista o no un peligro concreto de que tal audiencia pudiera frustrar la efectividad de las medidas reclamadas. Esto es, la justificación de la especial necesidad de solicitar y obtener la medida cautelar antes incluso de presentar la correspondiente demanda no conlleva implícitamente consigo el especial peligro de inefectividad que la audiencia al demandado supone.

\section{B) La excepcionalidad de la tutela cautelar ante causam en el plano transfronterizo}

44. En el proceso civil transfronterizo, la ausencia de una mejor regulación de la tutela cautelar en manos del órgano con competencia judicial internacional para conocer del asunto principal también ha motivado dudas y cuestionamientos a la hora de analizar ese doble régimen entre el foro principal y el foro auxiliar en materia de medidas cautelares previas a la demanda.

45. Respecto a la facultad cautelar del foro principal, ya hemos visto que el Reglamento guarda silencio, de modo que si no prevé expresamente dicha facultad, menos aún puede esperarse del legislador europeo que se pronuncie sobre la posibilidad de solicitar medidas cautelares con carácter previo a la interposición de la demanda ante el foro competente para conocer del fondo del asunto, así como sobre la exigencia de que la pretensión principal sea interpuesta en un determinado plazo una vez acordadas aquéllas.

46. Ante tal silencio, hay quienes han defendido la eficacia transfronteriza de las medidas cautelares acordadas por parte del tribunal competente para el fondo del asunto aun antes de conocer del mismo porque "la férrea ligazón de esta tutela ante causam a la posterior interposición de la demanda encaja perfectamente con esa noción de la accesoriedad e instrumentalidad sobre la que ha insistido tan-

\footnotetext{
${ }^{41}$ AAP Madrid, secc. $28^{\text {a }}$, de 22 de enero de 2010.

${ }^{42}$ Para V. Pérez Daudí (“El proyecto de Ley de enjuiciamiento civil...”, op. cit., p. 5 y ss.) la adopción de medidas cautelares previas debiera ser siempre inaudita parte. J. Garberí Llobregat, Las Medidas Cautelares en la Nueva Ley..., op. cit., p. 107, también defiende que las medidas cautelares preprocesales se han de adoptar por los tribunales en todo caso sin prestar previa audiencia al futuro demandado.
} 
to el tribunal de Luxemburgo ${ }^{43}$ ". Pero también hay quienes la rechazan hasta que no se demuestre que el tribunal que las adoptó es el conocedor del asunto principal, porque dicha facultad previa no garantiza el principio de seguridad jurídica y la previsibilidad del foro previo al juicio, y permitiría a los jueces aún no competentes en virtud de una norma de competencia del Reglamento acordar medidas provisionales o cautelares más allá de los límites establecidos por el Tribunal de Justicia ${ }^{44}$.

47. Este problema se ve agravado, a nuestro parecer, porque otros instrumentos europeos sí se pronuncian expresamente sobre la posible adopción de medidas cautelares ante causam y la exigencia de que la pretensión principal sea interpuesta en un determinado plazo una vez acordadas las medidas previas, como por ejemplo sucede en la Directiva 2004/48/CE relativa al respeto de los derechos de propiedad intelectual, en el Reglamento (UE) 655/2014 por el que se establece el procedimiento relativo a la orden europea de retención de cuentas a fin de simplificar el cobro transfronterizo de deudas en materia civil y mercantil o en la Directiva (UE) 2016/943 relativa a la protección de los conocimientos técnicos y la información empresarial no divulgados (secretos comerciales) contra su obtención, utilización y revelación ilícitas.

48. La primera de estas normas, en su art. 9.5, dispone que «Los Estados miembros garantizarán que las medidas provisionales a las que se refieren los apartados 1 y 2 se revoquen o, cuando menos, se suspendan sus efectos a petición del demandado, si el solicitante no interpone en un plazo razonable una acción sobre el fondo ante la autoridad judicial competente, plazo que determinará la autoridad judicial que ordene las medidas, cuando la legislación de un Estado miembro así lo permita, o, en ausencia de dicha determinación, en un plazo que no supere los 20 días hábiles o 31 días naturales, si este último fuera mayor».

49. La segunda de ellas, el art. 10.1 del Reglamento regulador de la orden europea de retención de cuentas, establece que «Cuando el acreedor haya solicitado una orden de retención antes de incoar el procedimiento sobre el fondo del asunto, incoará dicho procedimiento y acreditará dicha incoación al órgano jurisdiccional ante el que presentó la solicitud de orden de retención en el plazo de 30 días a partir de la fecha de presentación de la solicitud o, si la fecha es posterior, en el plazo de 14 días a partir de la fecha en que se dictó la orden. El órgano jurisdiccional podrá asimismo, previa solicitud del deudor, ampliar dicho plazo, por ejemplo, para permitir a las partes que lleguen a un acuerdo sobre la demanda, e informará a las dos partes consecuentemente».

50. $Y$ en tercer lugar, el art. 11.3.a) de la Directiva sobre secretos empresariales también se refiere a la posibilidad de dejar sin efecto las medidas cautelares previas, a instancia de la parte demandada, «si la parte demandante no ejercita una acción conducente a una resolución sobre el fondo del asunto ante la autoridad judicial competente en un plazo razonable determinado por la autoridad judicial que haya ordenado las medidas, cuando la legislación del Estado miembro así lo permita o, en ausencia de dicha determinación, en un plazo no superior a 20 días hábiles o 31 días naturales, si este último plazo es mayor».

51. No cabe duda de que el Reglamento regulador de la orden europea de retención de cuentas habilita, sin necesidad de previsión expresa de la legislación nacional, a solicitar la medida cautelar con anterioridad a la pretensión principa ${ }^{45}$. Y entendemos que la alusión en las Directivas sobre derechos de

\footnotetext{
${ }^{43}$ J. PÉrez GAIPO, “Tutela cautelar en el reglamento de Bruselas I Bis: ¿Un concepto amplio o restrictivo?”, en VV.AA., $L a$ cooperación procesal internacional en la sociedad del conocimiento, (coord. I. GonzÁlez Pulido; Dir. F. Bueno DE MATA), Atelier, 2019, p. 80. También Calvo Caravaca y González Carrascosa ("Medidas provisionales y cautelares y Reglamento Bruselas I-bis", op. cit., p. 63) estiman que las medidas pueden acordarse por el juez que ya está conociendo del asunto o del juez que podría conocer del fondo del asunto en virtud de un foro de competencia judicial internacional recogido en el Reglamento.

${ }^{44}$ N. NISI, "I provvedimenti provvisori e cautelari nel nuovo Regolamento Bruxelles I-bis", Cuadernos de Derecho Transnacional (Marzo 2015), Vol. 7, $\mathrm{N}^{\circ}$ 1, p. 140.

${ }^{45}$ F. CORdón Moreno ("La orden europea de retención de cuentas en un proceso seguido en España: ¿naturaleza cautelar o ejecutiva?”, Revista Española de Derecho Internacional, Vol. 69/2, julio-diciembre 2017, p. 303) afirma que la orden de
} 
propiedad intelectual y sobre secretos empresariales a "cuando la legislación de un Estado miembro así lo permita" debe entenderse referida a la posibilidad de que el plazo para interponer la demanda principal no venga fijado legalmente, sino que pueda ser determinado por la autoridad judicial, y no a que el ordenamiento interno prevea la adopción de medidas cautelares con carácter previo a la iniciación del litigio principal. De lo contrario, no tendría sentido que la norma europea incluyera un plazo concreto sobre algo no previsto.

52. Respecto al foro auxiliar del art. 35 del Reglamento Bruselas I bis, también se ha discutido que puedan solicitarse medidas cautelares cuando el asunto principal aún no ha quedado residenciado ante los tribunales de otro Estado. De nuevo, y ante este silencio, se ha señalado que habrá de estarse a lo establecido en la regulación nacional interna ${ }^{46}$, y sucede que en la legislación española, si bien el art. 730 LEC habilita con carácter general la posibilidad de solicitar medidas antes de interponer la demanda o después, comprobamos como el art. 722.II LEC requiere que el solicitante cautelar acredite ser parte de un proceso jurisdiccional extranjero, lo cual tendrá lugar tras la interposición de la demanda, pero nunca antes.

53. La exégesis de la expresión "Sin perjuicio de las reglas especiales previstas en los Tratados y Convenios o en las normas comunitarias que sean de aplicación" pasa por interpretar que, salvo Tratado o Convenio Internacional aplicable que expresamente permita la adopción de medidas cautelares previas al proceso, tal y como sucede por ejemplo en el Convenio Internacional sobre Embargo Preventivo de Buques de 1999 (art. 7), la legislación española impide la adopción de medidas cautelares previas a la demanda en aquellos supuestos en que el proceso principal deba tramitarse ante un tribunal extranjero, habida cuenta del tenor literal del art. 722.II LEC ${ }^{47}$.

54. Pero también cabe argumentar que la legislación interna española no puede contradecir en ningún caso la normativa europea, ya que «la aplicación de las normas procesales nacionales no puede ir en detrimento de la eficacia del Convenio ${ }^{48}$ 》, y dicha normativa europea nada señala respecto a la exigencia de que el litigio principal esté ya sustanciado y a la necesidad de ser parte en el proceso principal. La excepción prevista en el art. 35 RB I-bis permite solicitar medidas cautelares a los tribunales de un Estado miembro «incluso si un órgano jurisdiccional de otro Estado miembro es competente para conocer del fondo del asunto»; exige competencia para conocer, pero no que el asunto esté ya lite pendente.

55. En apoyo de esta solución podría añadirse que la adopción de medidas cautelares previas a la demanda está pensada para aquellos casos en que se acrediten especiales razones de urgencia y necesidad, y la necesidad de que el proceso principal deba seguirse ante un tribunal extranjero podría servir para justificar dicha urgencia y necesidad, pues ya hemos comprobado que el elemento transfronterizo supone un incremento de los riesgos de inefectividad ${ }^{49}$.

retención podrá pedirse (y acordarse), de acuerdo con las previsiones del Reglamento núm. 655/2014, ante litem o durante la pendencia del procedimiento (de declaración), y siempre inaudita parte debitoris (art. 11), sin necesidad, además, a diferencia de lo que ocurre en Derecho interno, de justificar razones de urgencia o necesidad".

${ }^{46}$ F. J. Garcimartín Alférez, F.J., El régimen de las medidas cautelares..., op. cit., p. 45; F. Gascón Inchausti, Medidas cautelares del proceso civil extranjero, op. cit., p. 420; M. Ortells Ramos, Las medidas cautelares, La Ley, Madrid, 2000 , p. 76 y ss. Por su parte, Fernández-Ballesteros López (Comentarios a la nueva Ley de Enjuiciamiento Civil, tomo III, ed. Iurgium, Barcelona, 2000, p. 3242) lo considera «tal vez incompatible con el tenor literal del art. 24 del Convenio de Bruselas, pero razonable».

${ }^{47}$ En el mismo sentido, vid., V. Pérez Daudí, V., "Las medidas cautelares en los procesos internacionales", Práctica de Tribunales, núm. 133, julio-agosto 2018, p. 5.

48 STJUE Hagen de 15 de mayo de 1990 (C-365/88), apartado 20.

49 Para Gascón Inchausti (“Artículo 35”, en VV.AA., Comentario al Reglamento (UE) $n^{\circ} 1215 / 2012$..., op. cit., p. 701), el régimen del art. $35 \mathrm{RB}$ está pensado para acudir al Estado "donde deban desplegar sus efectos las medidas cautelares a las que se aspira, tal vez de manera urgente, tal vez, incluso, inaudita parte debitoris (...) cuando el proceso sobre el fondo ya se desarrolla o se desarrollará en breve ante los tribunales de otro Estado o, dicho con menos palabras, lite alibi pendente sive penditura". 
56. En el arbitraje, una interesante consecuencia de considerar al sistema español como un foro «arbitration friendly» puede conducir a que se defienda la adopción de medidas cautelares ante causam en apoyo de un arbitraje extranjero, pues frente al tenor literal del art. 722.II LEC, la cláusula del art. $1.2 \mathrm{LA}^{50}$ incluye al art. 8 (adopción judicial de medidas cautelares), de manera tal que las partes que han decidido someter a arbitraje su controversia podrían, aún con anterioridad al inicio de las actuaciones arbitrales, acudir a los tribunales españoles para obtener medidas cautelares que aseguren lo que en su momento pueda declararse en el laudo arbitral ${ }^{51}$.

57. En la mediación, la STJUE Alassini $^{52}$ señaló que el artículo 5, apartado 2, de la Directiva 2008/52 no se oponía a aquella legislación nacional que estipule la obligatoriedad de la mediación o que la someta a incentivos o sanciones, ya sea antes o después de la incoación del proceso judicial, siempre que tal legislación no impida a las partes el ejercicio de su derecho de acceso al sistema judicial. Y que un sistema nacional que imponga, para determinados litigios, la tramitación previa de un procedimiento de conciliación extrajudicial no es contrario al Derecho de la Unión Europea cuando dicho procedimiento, entre otros aspectos, permita adoptar medidas provisionales en aquellos supuestos excepcionales en que la urgencia de la situación lo exija.

58. Si se considera compatible con el Derecho de la Unión Europea la existencia de una mediación o conciliación previas al proceso; que las mismas puedan ser obligatorias para determinadas materias (siempre que luego no se impida el acceso a la vía jurisdiccional); y que las mismas no impidan solicitar medidas cautelares, entendemos que estos argumentos permiten la solicitud de medidas cautelares ante demandan.

59. En España, el actual art. 10.2 de la Ley $5 / 2012$ de Mediación en Asuntos Civiles y Mercantiles se refiere a la posibilidad de solicitar medidas cautelares durante el tiempo en que se desarrolle la mediación, pero deja sin resolver la cuestión acerca de cómo proceder cuando se insten medidas cautelares previas a la demanda, y en vez de interponer aquélla, se inicie un procedimiento de mediación antes de acudir a los tribunales. Y es que la LEC no prevé expresamente la iniciación de la mediación como motivo de suspensión del plazo para interponer la demanda (art. 730.2.II LEC) ni como supuesto en el que no rige dicho plazo (art. 730.3 LEC), de modo que, a falta de una solución legal, estimamos que cabría considerar que el beneficiario de la tutela cautelar previa, durante la solicitud o formación de una mediación, tendrá un «deber de diligencia» similar a lo previsto en el arbitraje (es decir, informar al órgano judicial que acordó la medida cautelar acerca de que ha iniciado o instado la formación de un procedimiento de mediación y llevar a cabo las actuaciones tendentes a poner en marcha dicho procedimiento).

60. Además, y lege ferenda, vemos como el Anteproyecto de Ley de impulso de la Mediación aprobado por el Consejo de Ministros a comienzos de 2019 proponía la modificación de la LEC para, precisamente, permitir la solicitud de medidas cautelares, no sólo a quien sea parte en un procedimiento de mediación, sino también a «quien acredite ser parte de un pacto de mediación o de un convenio arbitral con anterioridad a las actuaciones de la mediación o arbitrales». Es decir, la voluntas legislatoris parece ir en esa dirección de admitir la solicitud de medidas cautelares antes de someter la cuestión principal a un proceso judicial o extrajudicial de resolución de conflictos.

${ }^{50}$ «Las normas contenidas en los apartados $3 .^{\circ}, 4 .^{\circ}$ y $6 .^{\circ}$ del artículo 8, en el artículo 9, excepto el apartado 2, en los artículos 11 y 23 y en los títulos VIII y IX de esta ley se aplicarán aun cuando el lugar del arbitraje se encuentre fuera de España».

${ }^{51}$ A favor de la posibilidad de la solicitud de medidas cautelares con anterioridad a la pendencia arbitral, L. A. CuCARELLA Galiana, El procedimiento arbitral (Ley 60/2003, de 23 de diciembre, de arbitraje), ed. Publicaciones del Real Colegio de España, Bolonia, 2004.

${ }^{52}$ STJUE Alassini y otros, de 18 de marzo de 2010 (asuntos acumulados C-317/08, C-318/08, C-319/08 y C-320/08). 


\section{Limitaciones a la tutela cautelar inaudita parte debitoris}

\section{A) La doctrina «Denilauler» y el rechazo al exequátur de medidas cautelares inaudita parte}

61. Uno de los elementos que más contribuye a dotar de eficacia práctica a la tutela cautelar es el «efecto sorpresa» con que las mismas puedan ser obtenidas. De ahí la explícita posibilidad que nuestra legislación prevé a la hora de solicitar medidas cautelares «junto con» la demanda principal, y no «en» la demanda. Ello permite la solicitud de medidas cautelares, al mismo tiempo de interponer la demanda pero en un escrito separado, y no ya mediante el tradicional Otrosí dentro de la misma, cuando se pretenda la adopción inaudita parte de las medidas.

62. Esa búsqueda del efecto sorpresa también se prevé expresamente en la facultad recogida en el segundo inciso del art. 732.2 LEC, cuando la pretensión principal se dirija a obtener la cesación de conductas que se reputen como publicidad ilícita, competencia desleal, o violen un determinado derecho de la propiedad industrial o intelectual: el solicitante cautelar puede reclamar al tribunal que requiera los informes u ordene las investigaciones que el solicitante no pueda aportar o llevar a cabo por sí mismo y que resulten necesarias para resolver sobre la solicitud, con carácter urgente y sin dar traslado del escrito de solicitud.

63. La solicitud inaudita parte debitoris de la tutela cautelar se constituye así en una eficaz herramienta para dotar de gran efectividad al aseguramiento de lo que se pretenda en el proceso principal. A cambio de ello, los requisitos para la adopción de medidas cautelares sin dar audiencia al demandado se ven aumentados. La urgencia y necesidad requeridas se aproximan a lo señalado al analizar la solicitud cautelar previa a la demanda principal, pero no debe confundirse. El periculum in mora «cualificado», en el caso de las medidas solicitadas inaudita parte, no trata de conjurar el riesgo derivado de la tramitación del propio procedimiento cautelar ordinario, sino el riesgo que pudiera producir la audiencia al demandado para la efectividad de la propia medida cautelar.

64. En el plano transfronterizo, sin embargo, se ha criticado el hecho de que la «doctrina Denilauler» estableciera una importante limitación para el exequátur de resoluciones cautelares adoptadas inaudita parte, por cuanto dicha Sentencia declaró que «los requisitos a los que el Título III del Convenio subordina el reconocimiento y la ejecución de las resoluciones judiciales no concurren en las medidas provisionales y cautelares decretadas o adoptadas por un órgano jurisdiccional sin que la parte contra la que vayan dirigidas haya sido citada a comparecer y que estén destinadas a ejecutarse sin haber sido previamente notificadas a esta última parte. De ahí se desprende que esta clase de resoluciones judiciales no puede acogerse a la ejecución simplificada prevista en el Título III del Convenio ${ }^{53}{ } »$.

65. Ello daba lugar a una tutela cautelar débil en el espacio judicial europeo ${ }^{54}$, lo cual fue objeto de importantes críticas y motivo de consultas y propuestas para mejorar los instrumentos europeos referidos a la libre circulación de las resoluciones provisionales y cautelares en la Unión Europea ${ }^{55}$.

66. En efecto, el Libro Verde sobre la revisión del Reglamento 44/200156, lanzado en abril de 2009 por la Comisión, planteaba la posibilidad de que las medidas cautelares ex parte pudieran ser reconocidas y ejecutadas en virtud del Reglamento, "siempre que el demandado tenga la posibilidad de

\footnotetext{
${ }^{53}$ STJUE Denilauler, de 21 de mayo de 1980 (Asunto C-125/79), aptdo. 17.

${ }^{54}$ Vid., por todos, A. L. Calvo Caravaca y J. González Carrascosa, "Medidas provisionales y cautelares y Reglamento Bruselas I-bis", op. cit., p. 72.

55 G. CuniBerti "La ejecución de las medidas provisionales y cautelares extranjeras en materia civil y mercantil en Europa", Diario La Ley, № 7601, de 31 de marzo de 2011, califica la doctrina sentada por el TJCE en el asunto Denilauler como "un precedente molesto" hasta que el legislador europeo lo remedie y se hacía eco de la propuesta de revisión del Reglamento Bruselas I, de 14 de diciembre de 2010 que expresamente preveía eliminar dicha condición.

${ }^{56} \operatorname{COM}(2009) 175$ final.
} 
impugnarlas posteriormente, particularmente a la luz de lo dispuesto en el artículo 9, apartado 4, de la Directiva 2004/48/CE". Y como sabemos, dicho art. 9.4 prevé la revisión de la medida acordada sin oír a la parte contraria, a solicitud de ésta y en un plazo razonable tras la notificación de las medidas, de un modo similar a lo previsto internamente en nuestro art. 739 LEC.

67. En la Propuesta de Reglamento presentada por la Comisión en diciembre de 2010 se buscaba la "clarificación de las condiciones en que pueden circular en la UE las medidas provisionales y cautelares" como uno de los objetivos concretos de la reforma, para lo cual se afirmaba que "Con respecto a las medidas provisionales, en particular las medidas cautelares, la propuesta establece la libre circulación de las medidas concedidas por un tribunal competente sobre el fondo del asunto, y especialmente - en determinadas condiciones - las medidas concedidas ex parte".

68. De entre las reformas planteadas en dicha Propuesta, el proyectado artículo 2 indicaba expresamente lo siguiente: «A los efectos del capítulo III, el término «resolución» engloba las medidas provisionales o las medidas cautelares ordenadas por un tribunal competente, en virtud del presente Reglamento, para conocer sobre el fondo del asunto. Incluye asimismo las medidas ordenadas sin que el demandado fuere citado a comparecer y que estuvieren destinadas a ser ejecutadas sin necesidad de notificación previa al demandado, siempre que este tuviere derecho a impugnar posteriormente la medida en virtud del Derecho nacional del Estado miembro de origen».

69. En la misma línea, el proyectado art. 42.2 exigía al solicitante de la ejecución en otro Estado miembro de una resolución que ordenare una medida provisional o cautelar, que aportase a las autoridades encargadas de dicha ejecución un certificado expedido por el tribunal de origen, con una descripción de la medida y que «ii) en caso de que la medida fuere ordenada sin que se cite al demandado a comparecer y debiere ser ejecutada sin notificación previa a este, que el demandado tiene derecho a impugnar la medida en virtud de la ley del Estado miembro de origen».

70. $\mathrm{Y}$ en la misma dirección, en el seno de la iniciativa de los Institutos UNIDROIT y ELI para el desarrollo de unos principios del Proceso Civil Transnacional se conformó un específico Grupo de Trabajo sobre medidas cautelares y provisionales en cuyo primer informe (noviembre 2014) ya se proponía, como apartado 8.2, la posibilidad de que la medida cautelar pudiera ser acordada ex parte, con la condición de que el sujeto pasivo de tal medida tuviera la oportunidad de impugnar dicha decisión lo antes posible ${ }^{57}$.

\section{B) Los avances del Reglamento Bruselas I bis respecto de las medidas cautelares con contradicción diferida}

71. El Reglamento Bruselas I bis mejoró la regulación jurídica a la tutela cautelar en la Unión Europea, aunque si lo comparamos con lo que se proponía en 2010 por parte de la Comisión en materia de medidas cautelares adoptables inaudita parte, resulta comprensible que el nuevo régimen cautelar haya sido calificado como "término medio 58 ".

72. Frente a la propuesta de 2010 de incluir, dentro del término «resolución»a los efectos de su exequátur en otro Estado miembro, "las medidas provisionales o cautelares ordenadas sin que el deman-

\footnotetext{
57 8.2. A court may order provisional relief without notice only upon urgent necessity and preponderance of considerations of fairness. The applicant must fully disclose facts and legal issues of which the court properly should be aware. A person against whom ex parte relief is directed must have the opportunity at the earliest practicable time to respond concerning the appropriateness of the relief.

58 "via di mezzo" según N. NISI (“I provvedimenti...”, op. cit., p. 140); “middle ground” para A. GERACI, G. GrasSI, F. LOMBARDI ("Juris(\&)prudence in provisional measures. Balancing effective protection and right to defense in the EU judicial space perspective". Themis Competition 2016, p. 6. Documento descargable de la página web: http://www.ejtn.eu/PageFiles/14777/ Written\%20paper_Italy.pdf. Fecha de consulta: 11 de mayo de 2020). Para PÉrEZ GAIPO (“Tutela cautelar...", op. cit., p. 81) el Reglamento Bruselas I bis "se queda a medias" y su solución choca con la propia razón de ser de este tipo de tutela cautelar.
} 
dado fuere citado a comparecer y que estuvieren destinadas a ser ejecutadas sin necesidad de notificación previa al demandado, siempre que este tuviere derecho a impugnar posteriormente la medida en virtud del Derecho nacional del Estado miembro de origen", el texto definitivo del art. 2.a RB I-bis matiza que el término «resolución», a dichos efectos, no incluye las medidas provisionales y cautelares que el órgano jurisdiccional acuerde sin que el demandado sea citado a comparecer, "a no ser que la resolución relativa a la medida haya sido notificada al demandado antes de su ejecución", y tal notificación vuelve a ser exigida en el art. 42.2.c (algo que el Estado de origen puede certificar en el apartado 4.5 del Anexo I al que se refiere el art. $53 \mathrm{RB}$ I-bis).

73. Este matiz resulta importante. No es lo mismo adoptar la medida y llevarla a la práctica sin ningún tipo de audiencia al sujeto pasivo de la misma (lo que la Propuesta de 2010 calificaba como ser ejecutadas sin necesidad de notificación previa al demandado), que adoptarla inaudita parte pero notificarla al demandado antes de su ejecución (lo que recoge el Reglamento de 2012) o fijar un plazo desde su notificación al demandado para que pueda impugnarla, tal y como sucede en el sistema procesal español (arts. 739 a 741 LEC). Si el demandado tuvo dicho plazo para impugnar tal resolución y voluntariamente no lo aprovechó, se ha considerado que dicha medida sí debería ser reconocida y ejecutada ante los tribunales del Estado requerido ${ }^{59}$. Y lo mismo sucederá cuando la medida cautelar haya sido adoptada sin dar audiencia a un tercero que resulta afectado por la ejecución: habrá que comprobar si el órgano adoptante de la medida (Estado de origen) le comunicó dicha resolución y si dicho tercero ha tenido o no posibilidad de recurrir ante dicho tribunal ${ }^{60}$.

74. Por ello, el sistema cautelar consagrado en el RB I-bis diferencia hasta tres supuestos de medidas cautelares, en función de las opciones disfrutadas por el sujeto pasivo de las mismas durante su discusión: a) las acordadas con audiencia del demandado en el Estado de origen, competente para conocer del fondo del asunto, que se reconocerán en el Estado de ejecución como cualquier otra resolución judicial; b) las acordadas inaudita altera parte y no notificadas al demandado, que no se considerarán una "resolución" a los efectos del Capítulo III; y c) las acordadas inaudita parte en el Estado de origen y notificadas al demandado antes de su ejecución, que también podrían desplegar efectos transfronterizos si el solicitante de su ejecución en el Estado requerido facilitase a las autoridades del Estado de ejecución una acreditación que pruebe esa notificación de la resolución al demandado ${ }^{61}$.

75. El segundo matiz importante del nuevo régimen jurídico en materia de medidas cautelares aprobado en 2012 lo encontramos en el Considerando n³3 RB I-bis. Aunque explica que "las medidas provisionales y cautelares ordenadas por dicho órgano jurisdiccional sin que el demandado haya sido citado a comparecer no deben reconocerse ni ejecutarse en virtud del presente Reglamento, a no ser que la resolución que contenga la medida sea notificada al demandado antes de su ejecución", a continuación especifica que "Esto no debe obstar al reconocimiento y ejecución de tales medidas en virtud del Derecho nacional".

76. Conforme a esta coletilla final, la medida cautelar adoptada inaudita parte en el Estado de origen, competente para conocer del fondo del litigio, también podría desplegar sus efectos en el Estado requerido si así lo admite su Derecho interno, aunque no se beneficiaría del régimen simplificado de circulación previsto en el RB I-bis ${ }^{62}$. En España, paradójicamente, el derecho interno aplicable en defecto

\footnotetext{
${ }^{59}$ F. J. Garcimartín Alférez, El régimen de las medidas cautelares..., op. cit., p. 144; M. Ortells Ramos, "La tutela cautelar en los procesos civiles con elementos extranjeros", Revista del Poder Judicial, 1998, n²4, p. 535; F. GASCÓN InCHAUSTI, "Capítulo X. Medidas cautelares (art. 31 RB)", op. cit., p. 336.

${ }^{60}$ Así lo admite expresamente la STJUE de 25 de mayo de 2016 (C-559/14, asunto Meroni).

${ }^{61}$ A. L. Calvo Caravaca y J. GonzÁlez Carrascosa, "Medidas provisionales y cautelares y Reglamento Bruselas I-bis", op. cit., pp. 73-74.

${ }^{62}$ Vid. A. Geraci, G. Grassi, F. Lombardi, “Juris(\&)prudence in provisional measures...”, op. cit., p. 6, que citan a F. GarCIMARTIN, The cross border effectiveness of inaudita altera parte measures in the Brussels I recast regulation: an appraisal, in The Brussels I Regulation Recast, Oxford, 2014, p. 182.
} 
de Tratado o Convenio internacional o instrumento europeo análogo - la Ley 29/2015, de 30 de julio, de cooperación jurídica internacional en materia civil- exige en su art. 41.4 que las medidas cautelares "se hubieran adoptado previa audiencia de la parte contraria", razón por la cual dicho régimen ha sido tildado de «sorprendente ${ }^{63} »$.

\section{Reflexión final: hacia la consagración de la tutela cautelar ante causam e inaudita parte en el Derecho Procesal Civil de la Unión Europea}

77. Con posterioridad a ese tímido avance del Reglamento 1215/2012 a la hora de facilitar, con matices, la libre circulación de las medidas cautelares y provisionales acordadas inaudita altera parte, se han aprobado nuevos instrumentos legales y determinadas iniciativas en el seno de la Unión Europea que nos permiten concluir que existe un deseo de impulsar un régimen unitario de la tutela cautelar en el Espacio judicial europeo como una herramienta más dentro del Derecho Procesal Civil de la UE para facilitar la efectividad de las resoluciones judiciales y extrajudiciales en los litigios transfronterizos, y que, dentro del mismo, tendría cabida — serían caracteres comunes - tanto la tutela cautelar solicitable ante causam como la adoptable inaudita parte.

78. Si bien el camino seguido hasta ahora en materia de armonización pasaba por la aproximación de los ordenamientos nacionales a través de las herramientas legislativas europeas (la «comunitarización» y posteriormente «europeización» de los procesos civiles nacionales), la tutela cautelar representa un ámbito en el que puede apreciarse la tendencia de buscar la convergencia del Derecho Procesal Civil de la Unión Europea con las realidades nacionales de los Estados miembros que ya constituyen una práctica asentada y ampliamente armonizada. Es decir, debe entenderse como un camino de dos direcciones: la tradicional adecuación de los ordenamientos nacionales a los estándares mínimos fijados por el legislador europeo y asentados por la jurisprudencia del TJUE, pero también la recepción por el propio Derecho de la Unión Europea de lo que constituye ya una realidad prácticamente uniforme en los ordenamientos nacionales de los Estados miembros.

79. La solicitud de medidas cautelares ante causam y su adopción inaudita altera parte constituyen sendas realidades recogidas por los códigos procesales civiles de los Estados miembros, cuyos tribunales nacionales han validado su adecuación a los estándares constitucionales de protección de las garantías procesales de los sujetos afectados por las mismas ${ }^{64}$, de modo no sólo deberían considerarse compatibles con el Derecho de la Unión, sino incorporarse a los instrumentos europeos de cooperación judicial civil y ser objeto de una libre circulación y reconocimiento en el espacio judicial europeo.

80. Como se ha visto, el régimen de las medidas cautelares en el Derecho Internacional Privado siempre ha sido fuente de importantes debates y la "solución intermedia" recogida en el RB I-bis no ha dejado contento a nadie ${ }^{65}$. Por ello, procede avanzar en la consecución de un régimen europeo de medidas cautelares que facilite su exportabilidad en los litigios transfronterizos. Y el mejor camino para ello es fijar una serie de principios rectores mínimos de la tutela cautelar en un instrumento legal europeo capaz de asegurar una verdadera libre circulación de medidas cautelares en el espacio judicial europeo.

${ }^{63}$ L. García Gutiérrez, "La tutela cautelar...”, op. cit., p. 295, quien también habla de "inconsistencia del sistema".

${ }^{64}$ En España, la adopción inaudita parte de medidas cautelares fue declarada conforme al derecho a la tutela judicial efectiva por parte del Tribunal Constitucional mediante el ATC 186/1983, de 27 de abril. Para Garcimartín Alférez ("La competencia judicial para adoptar medidas cautelares: el caso Iberdrola vs. EDF”, $R C d, 2008$, n³, pp. 147-156) y GómEZ JENE (“Arbitraje, medidas cautelares y Reglamento Bruselas I", Diario La Ley, № 7601, de 31 de marzo de 2011), "Las medidas inaudita parte son conocidas en todos los ordenamientos europeos y han sido consagradas por el Tribunal Constitucional. Sería insólito pensar que el Reglamento Bruselas I ha querido acabar con ellas".

${ }^{65}$ Sobre el grado de insatisfacción de la doctrina con dicho régimen (referido al Convenio de 1968 y al Reglamento de 2001), vid. C. Honorati, "Provisional Measures and the recast of Brussels I Regulation: a missed opportunity for a better ruling”, Riv. dir. int. priv. e proc., 2012, p. 525 y la bibliografía allí citada. Accesible en: http://ssrn.com/abstract=2443137. 
81. El mejor ejemplo de este avance apreciado en las instituciones europeas lo representa la orden europea de retención de cuentas bancarias regulada en el Reglamento 655/2014; un instrumento respecto del cual se ha llegado a afirmar que el legislador europeo ha positivizado en él la doctrina sobre las medidas cautelares a la que se aspira en el Derecho Procesal Civil de la Unión Europea ${ }^{66}$ y que de su regulación cabe extrapolar no pocas previsiones para un posible futuro régimen común de medidas cautelares en la Unión Europea ${ }^{67}$.

82. No obstante, dicho Reglamento también constituye una evidencia de las dificultades para avanzar en el desarrollo de un régimen general de las medidas cautelares y provisionales en el Derecho Procesal Civil de la Unión Europea. Los trabajos UNIDROIT/ELI dan muestra de la dificultad a lo largo de los años para aprobar una norma europea que recogiera ese régimen cautelar europeo unificado y facilitar así una tutela cautelar unitaria en en el espacio judicial europeo.

83. Por ello, la orden europea de retención de cuentas bancarias representó un importante cambio de rumbo - y un enorme paso hacia adelante- al centrarse en establecer un régimen europeo unitario y detallado de una concreta medida cautelar. Pero lo que queremos poner de manifiesto al señalarle como ejemplo es que, tratándose de la avanzadilla para una futura tutela cautelar europea, observamos como el legislador europeo apuesta, dentro de esas líneas caracterizadoras, tanto por la posibilidad de su solicitud ante causam, como por la posibilidad de una adopción inaudita parte debitoris.

84. Decimos que se trata del mejor ejemplo de la tendencia aquí defendida porque es el primer Reglamento europeo que consagra expresamente la posibilidad de solicitar y obtener la tutela cautelar ante causam (art. 5), fijando el propio Reglamento el plazo para instar el posterior procedimiento principal y el deber del beneficiario de la medida de acreditar tal incoación al órgano jurisdiccional ante el que hubiera presentado la solicitud de orden (art. 10.1). Y en la misma dirección, también es el primer Reglamento europeo que garantiza el reconocimiento y ejecución transfronteriza de una medida cautelar acordada inaudita parte, lo cual ya no es una posibilidad a instancias del solicitante en función de lo que prevea el derecho procesal interno del Estado miembro en que se solicite, sino la única posibilidad (art. 11).

85. Tal y como declara expresamente el art. 22, «Una orden de retención dictada en un Estado miembro con arreglo al presente Reglamento - es decir, inaudita parte debitoris — será reconocida en los demás Estados miembros sin necesidad de procedimiento alguno y tendrá fuerza ejecutiva en los demás Estados miembros sin necesidad de una declaración de fuerza ejecutiva ${ }^{68} 》$. Aunque limitado al ámbito de una específica medida cautelar (la retención de cuentas bancarias), dicha norma puede servir de referencia a la hora de defender la validez de la contradicción diferida para asegurar ese efecto sorpresa tan importante en materia cautelar, y aún más en los litigios internacionales, facilitando su ejecución transfronteriza.

86. Otro ejemplo de esa nueva tendencia europea a reconocer expresamente la tutela cautelar ante causam la encontramos en el terreno de los procedimientos de insolvencia transfronterizos. Para mejorar la eficacia de los mismos, el Considerando $n^{\circ} 36$ del Reglamento 2015/848 sobre procedimientos de insolvencia indica expresamente que "El órgano jurisdiccional competente para abrir el procedimiento de insolvencia principal debe estar facultado para ordenar medidas provisionales y cautelares desde el momento mismo de la solicitud de apertura del procedimiento. Las medidas cautelares y provisionales, ya sean anteriores o posteriores al inicio del procedimiento de insolvencia, son importantes para garantizar la eficacia del mismo".

${ }^{66}$ F. Gascón InCHAUSTI, Derecho europeo y legislación procesal civil nacional: entre autonomía y armonización, Marcial Pons, 2018, p. 79.

${ }^{67}$ M. L. Villamarín López, "La orden europea de retención de cuentas y sus requisitos de acceso. A propósito de la reciente sentencia del TJUE de 7 de noviembre de 2019", en VV.AA., Ejecución de decisiones relativas a deudas monetarias en la Unión Europea Experiencia española y adopción de decisiones informadas (Dir. C. Otero GarCíA-CASTRILlón), Dykinson, 2020, p. 250.

${ }^{68}$ En el mismo sentido, F. Cordón Moreno, “La orden europea de retención de cuentas...”, op. cit., p. 308. 
87. Conforme a tal premisa, y aunque el art. 52 (Medidas cautelares) nada dice respecto a la posibilidad de que las medidas cautelares sobre bienes del deudor situados en otro Estado miembro sean acordadas inaudita parte, la remisión del art. 7 a la ley del Estado de apertura del procedimiento nos conduce a sostener que la tutela cautelar ante causam y la inaudita parte debitoris serán una constante generalizada. En el Derecho español, por ejemplo, el art. 17 de la Ley Concursal prevé la adopción de medidas cautelares, a petición del legitimado para instar el concurso necesario, al admitir a trámite la solicitud de declaración de concurso, lo cual tiene lugar antes de emplazar al deudor para que conteste la petición de concurso. Su remisión al régimen general de la LEC también apoya esta idea.

88. Finalmente, y dentro de ese camino de la armonización procesal civil en la Unión Europea, la Propuesta de Directiva sobre normas mínimas comunes de procedimiento civil en la Unión Europea, de julio de 2017, avanza en esa misma dirección iniciada por el Reglamento referido a la orden europea de retención de cuentas bancarias y plantea un modelo de tutela cautelar común en el Derecho de la Unión Europea, cuyos caracteres generales incluirían la tutela cautelar ante causam e inaudita parte.

89. Conforme al apartado $1^{\circ}$ del art. 6 de la citada Propuesta, las medidas cautelares y provisionales podrán ser acordadas "antes de que se inicie el procedimiento sobre el fondo del asunto y en cualquier fase de dicho procedimiento". Y conforme al apartado 30, "Los Estados miembros velarán por que, en casos debidamente justificados, se puedan adoptar medidas provisionales sin que el demandado sea oído, cuando el retraso pudiera ocasionar un daño irreparable al demandado, o cuando existe un riesgo demostrable de destrucción de pruebas".

90. Como vemos, el Parlamento vuelve a retomar en 2017 la idea recogida en la Propuesta de Reglamento del Parlamento Europeo y del Consejo relativo a la competencia judicial, el reconocimiento y la ejecución de resoluciones judiciales en materia civil y mercantil del año $2010^{69}$ en el siguiente sentido: a diferencia de la «doctrina Denilauler» y de la solución intermedia del Reglamento Bruselas I bis, conforme a las cuales la tutela cautelar adoptada inaudita parte sería objeto de ejecución transfronteriza sólo cuando hubiera sido notificada al deudor "antes de su ejecución" (Considerando n 33 y art. 2.a RB I-bis), la Propuesta defiende que la notificación al deudor de la medida cautelar acordada inaudita parte sea notificada "tras la ejecución de las medidas", y que sea a instancia del demandado cuando pueda producirse una revisión de la tutela cautelar acordada, tal y como prevé el régimen procesal español de los arts. 739 a 741 LEC.

91. El mensaje lanzado desde el Parlamento Europeo parece claro: a la hora de aproximar las legislaciones procesales civiles nacionales para garantizar el derecho a la tutela judicial efectiva de los arts. 47 CDFUE y 6 CEDH (recordemos que el mismo constituye el fundamento de la tutela cautelar), el régimen europeo cautelar a insertar en un hipotético Código Procesal Civil Europeo ${ }^{70}$, capaz de asegurar la eficacia transfronteriza de las medidas cautelares y provisionales adoptadas por el tribunal competente para conocer del fondo del asunto, revestiría como elementos básicos comunes muchos de los expresamente recogidos en la LEC española: justicia rogada, solicitud ante causam, adopción inaudita parte debitoris con posibilidad de contradicción diferida, exigencia de caución como regla general y responsabilidad del solicitante cautelar por los daños producidos con la ejecución de la medida.

\footnotetext{
${ }^{69} \operatorname{COM}(2010) 748$.

${ }^{70}$ Por ello se ha calificado como "un salto cualitativo de enorme trascendencia" (F. GASCÓn InCHAUstı, Derecho europeo y legislación procesal civil nacional..., op. cit., p. 78).
} 